\title{
Small molecule RL71 targets SERCA2 at a novel site in the treatment of human colorectal cancer
}

\author{
Baofang Yang ${ }^{1, *}$, Minxia Zhang ${ }^{1, *}$, Jian Gao ${ }^{1}$, Jiahuang Li ${ }^{1}$, Lu Fan ${ }^{1}$, Gang Xiang ${ }^{1}$, \\ Xingqi Wang ${ }^{1}$, Xiaoning Wang ${ }^{1}$, Xuefeng Wu ${ }^{1}$, Yang Sun ${ }^{1}$, Xudong Wu ${ }^{1}$, Guang \\ Liang $^{2}$, Yan Shen ${ }^{1}$ and Qiang $X \mathbf{u}^{1}$ \\ ${ }^{1}$ State Key Laboratory of Pharmaceutical Biotechnology, School of Life Sciences, Nanjing University, Nanjing, China \\ 2 Bioorganic and Medicinal Chemistry Research Center, School of Pharmaceutical Sciences, Wenzhou Medical College, \\ Wenzhou, China \\ * These authors have contributed equally to this work \\ Correspondence to: Qiang XU, email: molpharm@163.com \\ Yan Shen, email: shenyan@nju.edu.cn
}

Keywords: RL71, SERCA2, novel binding site, colorectal cancer, targeted agent

Received: May 09, $2015 \quad$ Accepted: September 26, $2015 \quad$ Published: October 10, 2015

This is an open-access article distributed under the terms of the Creative Commons Attribution License, which permits unrestricted use, distribution, and reproduction in any medium, provided the original author and source are credited.

\section{ABSTRACT}

While targeted agents are an important part of the treatment arsenal for colorectal cancer, there is still a lack of efficient small-molecule targeted agents based on the understanding of pathogenic molecular mechanisms. In this study, curcumin analog RL71 displayed potent cytotoxicity towards human colon cancer cells with an IC $_{50}$ of $0.8 \mu \mathrm{M}$ in SW480 cells and inhibited xenotransplanted tumor growth in a dosedependent manner. Using affinity chromatography, we identified sarco/endoplasmic reticulum calcium-ATPase (SERCA) 2 as the binding target of RL71. Most notably, RL71 demonstrated special binding to SERCA2 at a novel site with the lowest estimated free energy $-8.89 \mathrm{kcal} \mathrm{mol}^{-1}$, and the SERCA2 residues critical for RL71 binding were identified. RL71 suppressed the $\mathrm{Ca}^{2+}$-ATPase activity of SERCA2 both in vitro and in vivo, accompanied by the induction of endoplasmic reticulum stress leading to apoptosis and G2/M cycle arrest in SW480 cells. In addition, RL71 showed synergistic cytotoxicity with the pan-SERCA inhibitor thapsigargin. These results suggest that RL71 could be a selective small-molecule inhibitor of SERCA2, and that it may serve as a lead compound for the study of targeted colorectal cancer therapy.

\section{INTRODUCTION}

Colorectal cancer (CRC) is one of the most important causes of cancer mortality [1]. Other than surgical resection, current therapy for CRC mainly relies on traditional cytotoxic agents with limited effects. These considerations highlight the importance of developing new treatments based on the understanding of pathogenic molecular mechanisms.

Endoplasmic reticulum (ER) calcium homeostasis is involved in a multitude of signaling pathways that control cell growth, differentiation and apoptosis [2]. Sarco/ endoplasmic reticulum calcium-ATPases (SERCAs) act as $\mathrm{Ca}^{2+}$-ATPases that transfer $\mathrm{Ca}^{2+}$ from the cytosol to the lumen of the sarcoplasmic/endoplasmic reticulum at the expense of ATP hydrolysis. SERCA-dependent calcium transport is the only calcium-uptake mechanism in the ER, and therefore the regulation of SERCA activity is crucial to regulating calcium homeostasis in this organelle. Thus far, SERCA has been identified as a therapeutic target for prostate cancer and NOTCH1-mutated leukemia [3, 4]. Recent studies have reported that particular SERCA isoforms have altered expression patterns in various malignancies including CRC [5-7]. SERCA2 mRNA overexpression has been found both in cancerous tissues of CRC patients and in circulating tumor cells of relapsed CRC patients $[8,9]$. Additionally, increased SERCA2 protein expression is significantly correlated with serosal invasion, lymph node metastasis, and advanced tumor stage. Consistently, our previous study also demonstrates 
that increased SERCA2 protein levels correlate strongly with tumor progression in patients with CRC [10]. Meanwhile, the loss of SERCA3 expression is an early event during the multistep process of colon carcinogenesis [11]. SERCA3 expression is low in colorectal carcinoma compared with that in the adjacent non-neoplastic mucosa and adenoma [12]. Thus, increased SERCA2 expression could be a rational and feasible target for anti-CRC drug development.

A variety of pan-SERCA inhibitors such as thapsigargin (TG) have been identified with diverse chemical structures and binding affinity [13]. Given the pervasive role of calcium signaling in normal physiology, only TG and related derivatives have been implemented in the clinic to date [14]. One strategy might be the development of isoform-specific small-molecule inhibitors of SERCA. The natural product curcumin has anti-CRC activity and is also a SERCA inhibitor that is 6-fold more effective in inhibiting SERCA2b than SERCA3a [15]. Therefore, investigating the selective potencies of curcumin analogs may prove to be useful.

In this study, we identified a potent anti-CRC compound RL71 (3,5-bis(3,4,5-trimethoxybenzylidene)1-methylpiperidine-4-one) from a series of secondgeneration heterocyclic cyclohexanone curcumin analogs. Using affinity chromatography, we discovered that SERCA2 is the direct target of RL71. By computational virtual docking analysis and biological evaluation, RL71 was shown to interact with SERCA2 in the cleft on the lumenal side of the ER where Lys876 is critical for binding. The binding of RL71 at this novel site markedly inhibited SERCA2 activity and induced ER stressassociated apoptosis both in vitro and in vivo.

\section{RESULTS}

\section{RL71 shows potent cytotoxicity towards human colon cancer cells}

After a cell-based screen for cytotoxicity using a series of second-generation heterocyclic cyclohexanone curcumin analogs, we identified RL71 by its significant dose-dependent suppression of cell viability compared with curcumin in a panel of human colon cancer cell lines (Figure 1A, 1B; Table S1). Out of these cell lines, RL71 showed the lowest $\mathrm{IC}_{50}$ value $(0.8 \mu \mathrm{M})$ for inhibition of cell viability in the colon carcinoma line SW480. Timedependent inhibitory effects on cell viability were also confirmed in colon cancer cell lines SW480 and HCT116 (Figure 1C).

\section{Identification of SERCA2 as a cellular target of RL71}

To investigate the cellular target (or targets) of RL71, we attempted to generate biotinylated RL71 derivatives. Among 5 curcumin analogs, RL71 (1) exhibited the strongest cytotoxic effect on SW480 cells (Figure 2A). RL100 (3), which has a similar chemical structure except for the lack of a methyl substituent on the nitrogen, exhibited an approximate 16-fold weaker cytotoxicity than RL71. On the basis of their structures, we conjugated biotin to the nitrogen of RL71 to generate RL71-biotin (7) (Figure 2B). Although RL71-biotin showed decreased efficacy compared to RL71, RL71biotin still maintained significant cytotoxic activity at 1 $\mu \mathrm{M}$ in SW480 cells (Figure 2C). Total cell extracts from SW480 cells were used for the affinity chromatograph experiment. The proteins between 95 and $130 \mathrm{kDa}$ were specially purified on RL71-biotin-coupled streptavidin beads and competed with soluble RL71 (Figure 2D). LC/ MS analysis revealed that SERCA2 is a binding protein of RL71. This finding was confirmed by western blot analysis using an anti-SERCA2 antibody (Figure 2E). The interaction between RL71-biotin and SERCA2 could be competed by RL71. Because of the innate fluorescent property of RL71, immunofluorescence staining was performed to identify its subcellular localization. We observed that RL71 co-localized with SERCA2 (Figure 2F). Additionally, the co-localization of RL71 and ERtracker was revealed in SW480 cells (Figure S1). These results indicate that RL71 can potentially target SERCA2 in the ER.

To further explore the potential mode of binding of RL71 to the SERCA2 protein, we employed molecular docking using AutoDock 4.2. Based on the reported crystal structure of SERCA1 (Protein Data Bank (PDB) 3ar4) [16], we performed homology modeling for the SERCA2-RL71 complex, because the SERCA isoforms share over $75 \%$ homology at the amino acid level with similar domain structures. The model with the lowest estimated free energy for binding $\left(-8.89 \mathrm{kcal} \mathrm{mol}^{-1}\right)$ was selected. As shown in Figure 2G, RL71 appears to bind the cleft between the loop connecting M3 and M4 and the L78 loop on the lumenal side, possibly sealing the access pathway at the very surface through hydrogen bonds, hydrophilic interactions and Van der Waals forces with a group of residues. Our modeling analysis predicated that RL71 forms hydrogen bonds with Gln874, Lys876, Glu877 and Asp878. In addition, RL71's two phenyl rings could form Pi-Pi interactions with His278 and Phe872. To verify the importance of these residues in the binding of RL71, we generated SERCA2 mutants carrying H278A, Q874A and K876A mutations. As predicted by the model, the H278A and Q874A double mutant showed a reduced affinity for RL71-biotin (Figure 2H). Notably, we hardly detect any apparent binding between RL71-biotin and the 
H278A and K876A double mutant. These results indicate that RL71 possibly binds to SERCA2 at a novel site where amino acid Lys876 is critical for binding.

Our analysis also showed that the less active analog RL100 could dock into the same site in SERCA2 and form hydrogen bonds with side-chains of Gln874 and Lys876. It was observed that the nitrogen in RL100 could form a hydrogen bond with Asp281 (Figure S2). This interaction induces the deflection of the molecule, which broke hydrogen bonds with Glu877 and Asp878, and weakened the Pi-Pi interactions of His278 and Phe872.

\section{RL71 inhibits SERCA2 activity and induces ER stress-associated apoptosis}

To test the effects of RL71 on SERCA2 function, we measured the $\mathrm{Ca}^{2+}$-ATPase activity in the treated SW480 cells. RL71 significantly inhibited the $\mathrm{Ca}^{2+}$-ATPase activity in a dose-dependent manner (Figure 3A). Additionally, $4 \mu \mathrm{M}$ of RL71 inhibited the $\mathrm{Ca}^{2+}$-ATPase activity by $77 \%$, to a level comparable to $1 \mu \mathrm{M}$ of TG (Figure $3 \mathrm{~B}$ ). In contrast, the less active analog RL100 failed to show any inhibition. To further validate the inhibitory effect of RL71 on SERCA-associated $\mathrm{Ca}^{2+}$-uptake activity, we examined intracellular $\mathrm{Ca}^{2+}$ mobilization in treated SW480

A<smiles>COc1cc(/C=C2\CN(C)C/C(=C\c3cc(OC)c(OC)c(OC)c3)C2=O)cc(OC)c1OC</smiles><smiles>COc1cc(/C=C/C(=O)CC(=O)/C=C/c2ccc(O)c(OC)c2)ccc1O</smiles>

B
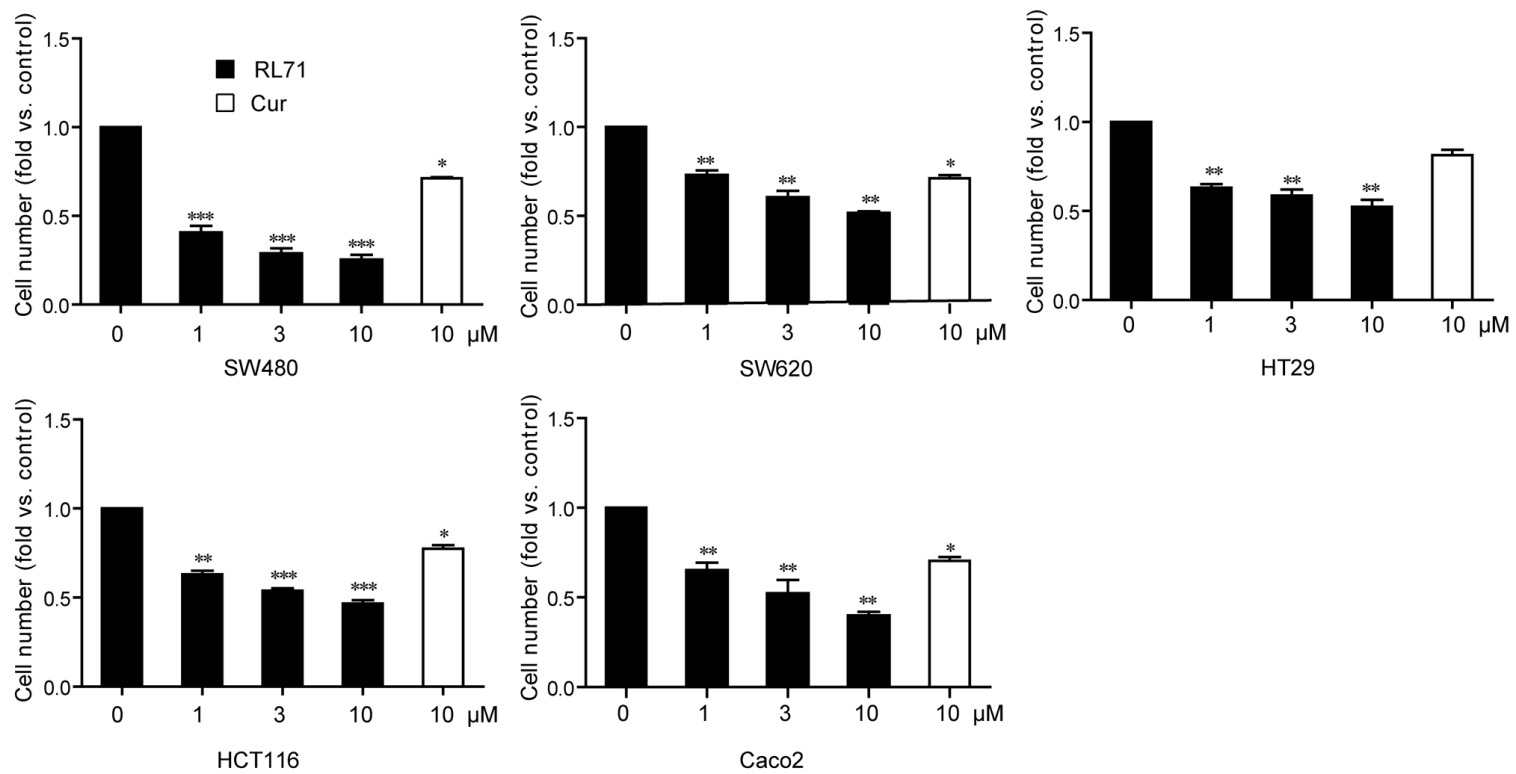

(2)

C
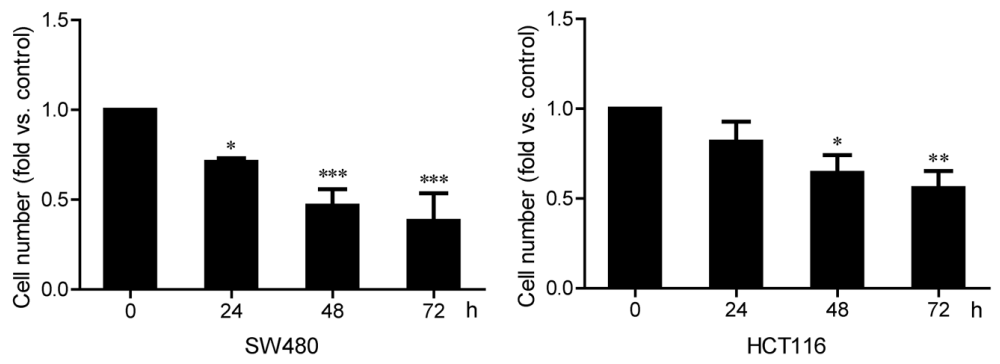

Figure 1: RL71 inhibits cell viability in human colon cancer cells. A. Chemical structures of RL71 (1) and curcumin (2). B. Dose-dependent cytotoxicity of RL71 in human colon cancer cell lines. Cell viability was determined by MTT assay after a $48 \mathrm{~h}$ treatment. Curcumin (Cur) was used as a control. C. Time-dependent cytotoxicity of RL71 (1 $\mu \mathrm{M})$ in SW480 and HCT116 cells. Data are the mean \pm SEM of three independent experiments. $* P<0.05, * * P<0.01, * * * P<0.001$ versus the control group without any treatment. 
cells. In $\mathrm{Ca}^{2+}$-free medium, RL71 induced a steady rise in cytosolic $\mathrm{Ca}^{2+}$ levels (Figure 3C). When the cells were pretreated with TG that depletes $\mathrm{Ca}^{2+}$ stores in ER, RL71induced $\left[\mathrm{Ca}^{2+}\right]_{i}$ increase was abolished (Figure 3D). These data suggest that the cytosolic influx is due to SERCA inhibition in ER, but not extracellular calcium influx.

The inhibition of SERCA causes a depletion of the
ER calcium storage pool and a subsequent rise in cytosolic calcium levels, which results in ER stress leading to apoptosis [17]. We thus tested the effects of RL71 on the ER stress-associated apoptotic signaling pathway in SW480 cells. Hoechst staining demonstrated that apoptotic changes in morphology occurred, characterized by typical chromatin condensation and blebbing nuclei in
A

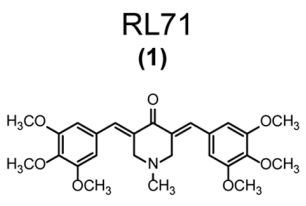

$\mathrm{IC}_{50}(\mu \mathrm{M}) \quad 0.8 \pm 0.2$

B<smiles>[R17][R17]([H])([H])[O-]</smiles>

(7)

C

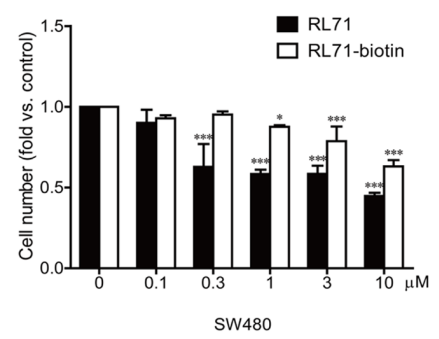

G

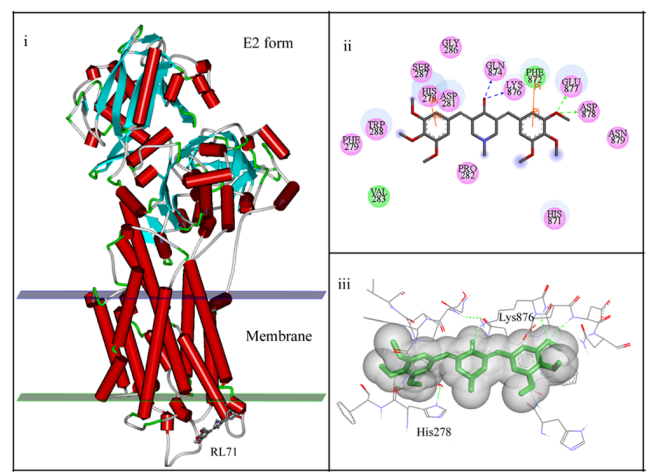<smiles>COc1cc(/C=C2/CNCC2(O)c2cc(OC)c(OC)c(OC)c2)cc(/C=C2\CNCC2=O)c1</smiles>

RL100

(3)

$13.2 \pm 1.9$

D

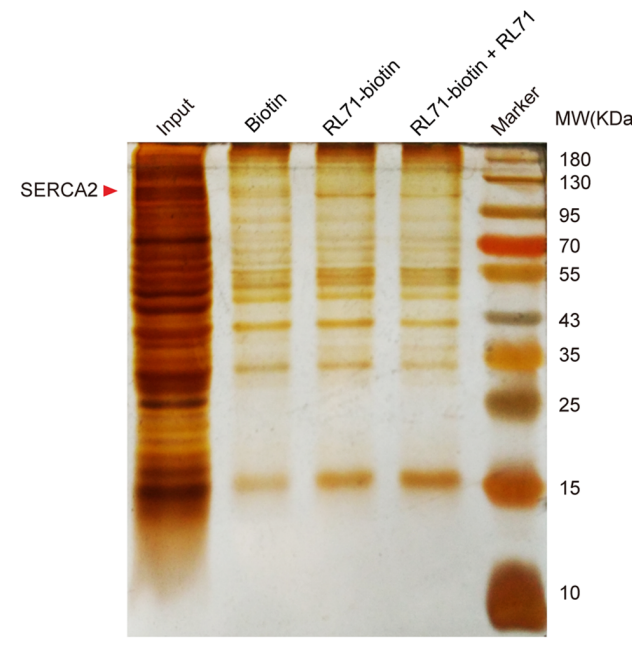

F36

(4)

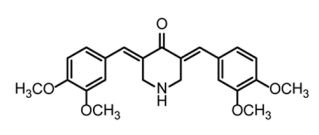

$6.3 \pm 1.1$
LH60

(5)<smiles>COc1cc(C=C2COC/C2=C\c2cc(OC)c(O)c(OC)c2)cc(OC)c1O</smiles>

$10.4 \pm 2.1$

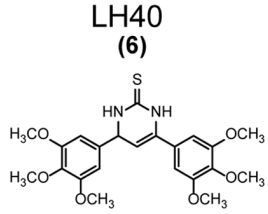

$1.5 \pm 0.6$

E $\begin{array}{rrrr}\text { Biotin } & + & - & - \\ \text { RL71-biotin } & - & + & + \\ \text { RL71 } & - & - & +\end{array}$

$\mathbf{F}$

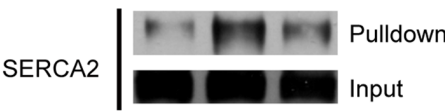

RL71

$40 \times$

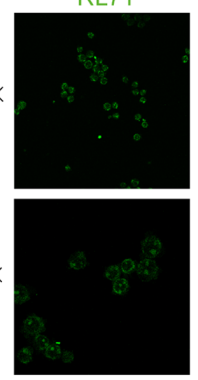

SERCA2
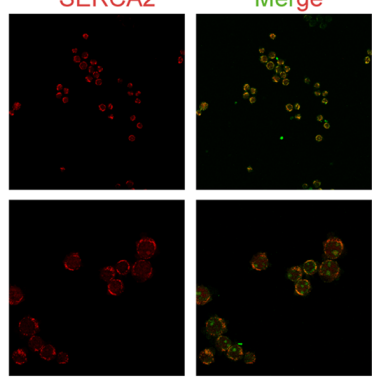

H

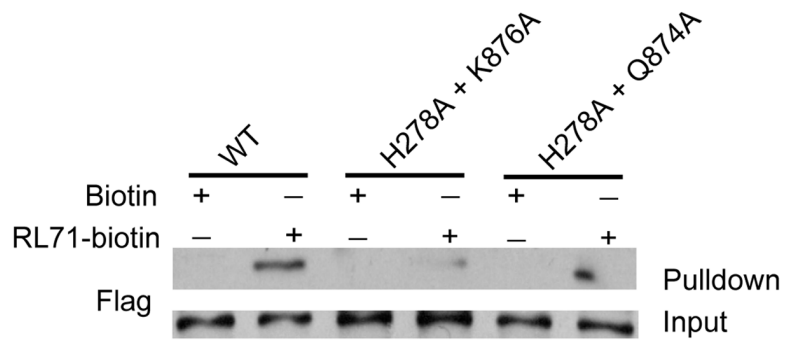

Figure 2: RL71 targets the SERCA2 protein. A. Cytotoxicity of RL71 analogs (3-6) in SW480 cells. The concentrations that cause a $50 \%$ inhibition $\left(\mathrm{IC}_{50}\right.$ ) of cell viability are shown. B. Chemical structure of biotinylated RL71 (RL71-biotin, 7). C. The effects of RL71 and RL71-biotin on SW480 cell viability. Cell viability was determined by MTT assay after a $24 \mathrm{~h}$ treatment. Data are the mean \pm SEM of three independent experiments. ${ }^{*} P<0.05, * * * P<0.001$ versus the control group without any treatment. D. Purification of RL71-binding proteins by affinity chromatography with 7-conjugated beads, which were incubated with the whole lysates of SW480 cells. Bound proteins were separated on an SDS gel and visualized by silver staining. E. Western blot analysis using the anti-SERCA2 antibody and the eluted proteins from D.. F. The co-localization of RL71 and SERCA2 in SW480 cells. The cells were treated with $10 \mu \mathrm{M}$ of RL71 for 2 h and stained with an anti-SERCA2 antibody. Confocal microscopy was performed after a $2 \mathrm{~h}$ incubation. G. Molecular docking analysis of RL71 and SERCA2. H. The binding affinity for RL71-biotin of the double mutants within the binding site. The whole lysates of the HEK293 cells overexpressing FLAG-tagged SERCA2b (WT) or its mutants were incubated with RL71-biotin and streptavidin beads. The bound fractions were separated by SDS-PAGE and analyzed by western blotting. 
RL71-treated SW480 cells (Figure S3A). RL71 treatment caused the accumulation of ubiquitinated proteins and increased GRP78, ATF4, and CHOP expression, as well as the cleavage of PARP, in a dose-dependent manner (Figure 3E). Because CHOP acts as a key transcription factor of DR5 under the condition of ER stress, we observed that RL71 treatment indeed caused an increase in DR5 protein levels (Figure S3B). The up-regulation of DR5, but not Fas, was confirmed on the surface of SW480 cells after RL71 treatment (Figure S3C). In addition, 4-phenylbutyric acid (PBA), a chemical chaperone reported to be an inhibitor of ER stress [18], reduced CHOP expression in RL71-treated SW480 cells (Figure S3D).

To evaluate the involvement of SERCA2 in RL-71-induced ER stress, we examined the effects of overexpression and knockdown of SERCA2 on the expression of ER stress-related molecules in RL71-treated SW480 cells. SERCA2 (predominantly the ubiquitous SERCA2b isoform) is always present in cancer and
A

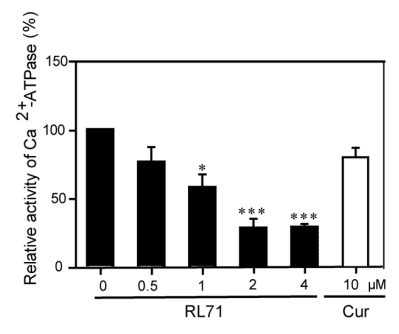

E

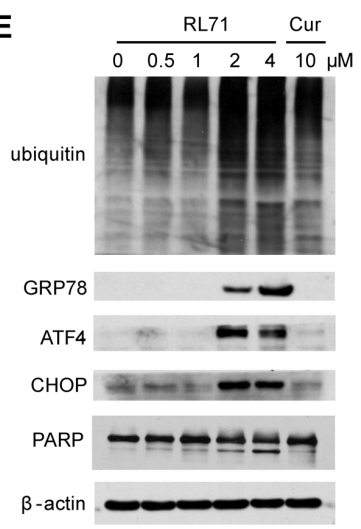

B

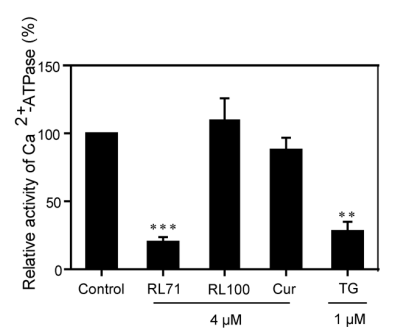

$\mathbf{F}$

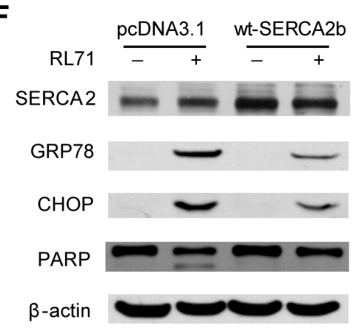

leukemia cell lines $[5,11,19]$. Real time-PCR confirmed the predominant expression of SERCA2b, and RL71 showed no effect on SERCA2 expression at either mRNA or protein levels in SW480 cells (Figures S4A and S4B). The overexpression of SERCA2b reduced the elevation of GRP78, CHOP expression and the cleavage of PARP in RL71-treated SW480 cells (Figure 3F). Moreover, stable SERCA2 knockdown blocked their up-regulation (Figure $3 \mathrm{G}$, left panel). RL71-associated cell growth inhibition was also reversed, at least in part, by SERCA2 knockdown (Figure 3G, right panel).

\section{RL71 targets SERCA2 at a novel site during ER stress-associated apoptosis}

To clarify the mechanism of action of RL71 during the induction of ER stress, we investigated the effects of SERCA2 mutants on ER stress-related molecules in
C

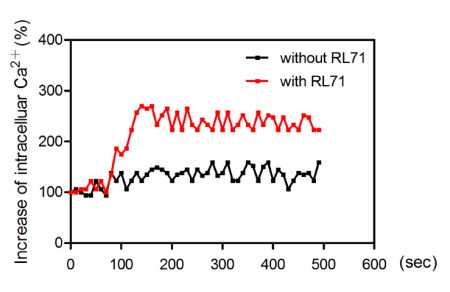

D

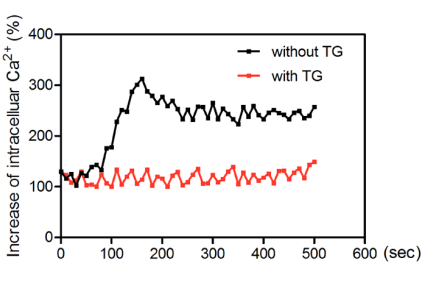

G
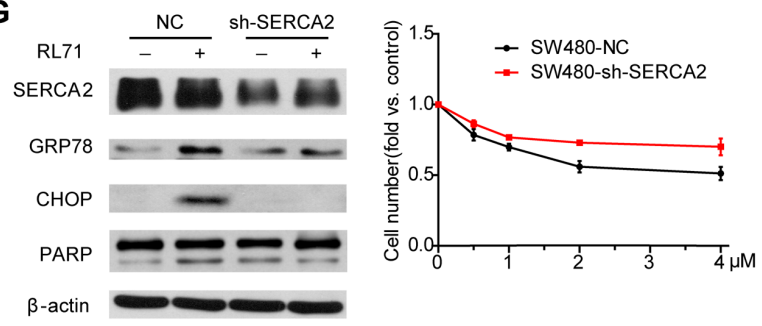

Figure 3: RL71 displays SERCA2-inhibiting activity and facilitates apoptosis by inducing ER stress in SW480 cells. A. The dose-dependent inhibitory effect of RL71 on $\mathrm{Ca}^{2+}$-ATPase activity. The cells were incubated with the indicated concentrations of RL71 or Cur for $24 \mathrm{~h}$. Then, the $\mathrm{Ca}^{2+}$-ATPase activity was measured according to the instructions of the $\mathrm{Ca}^{2+}$-ATPase kit provided by Nanjing Jiancheng Bioengineering Institute. B. The effects of the indicated compounds on $\mathrm{Ca}^{2+}$-ATPase activity. C. The increase of intracellular $\mathrm{Ca}^{2+}$ concentrations after RL71 treatment. Fura-2/AM loaded cells were stimulated with or without $2 \mu \mathrm{M}$ of RL71. The y-axes represent the percentage of intracellular $\mathrm{Ca}^{2+}$ concentration. The x-axes depict the time in seconds, with time 0 representing the time of RL71 addition. The data are representative of at least 3 experiments. D. Changes of $\left[\mathrm{Ca}^{2+}\right]_{\mathrm{i}}$ after pretreatment with vehicle or with $\mathrm{TG}(5 \mu \mathrm{M})$, followed by stimulation with $2 \mu \mathrm{M}$ of RL71. The data are representative of at least 3 experiments. E. The protein levels of ubiquitin-linked proteins, GRP78, ATF4, CHOP and PARP. Cells were treated with the indicated concentrations of RL71 or Cur for 24 h. F. The effects of SERCA2 overexpression on GRP78, CHOP and PARP expression. Cells were transiently transfected with pcDNA3.1 or SERCA2b expression plasmids. After $24 \mathrm{~h}$, the cells were incubated with $2 \mu \mathrm{M}$ of RL71 for another $24 \mathrm{~h}$. G. The effects of SERCA2 knockdown on GRP78, CHOP and PARP expression (left panel) and cell viability (right panel). Cells stably expressing control virus or sh-SERCA2 virus were incubated with $2 \mu \mathrm{M}$ of RL71 for $24 \mathrm{~h}$. The protein levels were measured by western blot. The cell survival rate was determined by MTT assay. The data are mean $\pm \mathrm{SEM}$ of three independent experiments. $* P<0.05,{ }^{*} P<0.01, * * * P<0.001$ versus control. All of the western blot analyses are representative of at least 3 experiments. 
transfected HEK293 cells. Unlike wild type SERCA2b, the $\mathrm{H} 278 \mathrm{~A}$ and K876A double mutant failed to reduce the elevation of GRP78 and CHOP expression upon RL71 treatment. In contrast, the H278A and Q874A double mutant blocked the up-regulation of GRP78 and CHOP to a lesser extent than wild type SERCA2b (Figure 4A). In addition, the H278A and K876A double mutant did not decrease the cytosolic $\mathrm{Ca}^{2+}$ levels induced by RL71 (Figure 4B). These results were consistent with the binding affinities of the RL71-SERCA2 mutant interaction, indicating that RL71 interacts directly with SERCA2 in the cleft on the lumenal side of ER where Lys 876 is critical for binding. The identity of this novel binding site was also supported by evidence showing that RL71 synergistic cytotoxicity with thapsigargin in SW480 cells (Figure 4C), which binds the E2 form of SERCA in the transmembrane domain [20].

\section{RL71 induces G2 cell-cycle arrest via ER stress}

Treating cells with drugs that target ER calcium influx results in ER stress, which induces G2 cell-cycle arrest via mRNA translation of the p53 isoform p53/47 [21]. Measurement of DNA content showed that RL71 indeed increased the percentage of cells in G2/M phase and decreased the percentage in $\mathrm{G} 0 / \mathrm{G} 1$ phase of the cell cycle in a dose-dependent manner (Figure 5A). An average increase of $60 \%$ in the proportion of SW480 cells in G2/M phase over control was observed upon incubation with RL71 $(0.5 \mu \mathrm{M})$ or curcumin $(10 \mu \mathrm{M})$. The overexpression of SERCA2b suppressed G2 cell-cycle arrest in RL71treated SW480 cells (Figure 5B). Like TG, RL71 induced p53/p47 mRNA translation (Figure 5C). These results demonstrate that RL71 induces ER stress by interfering with SERCA2 function (Figure 5D).

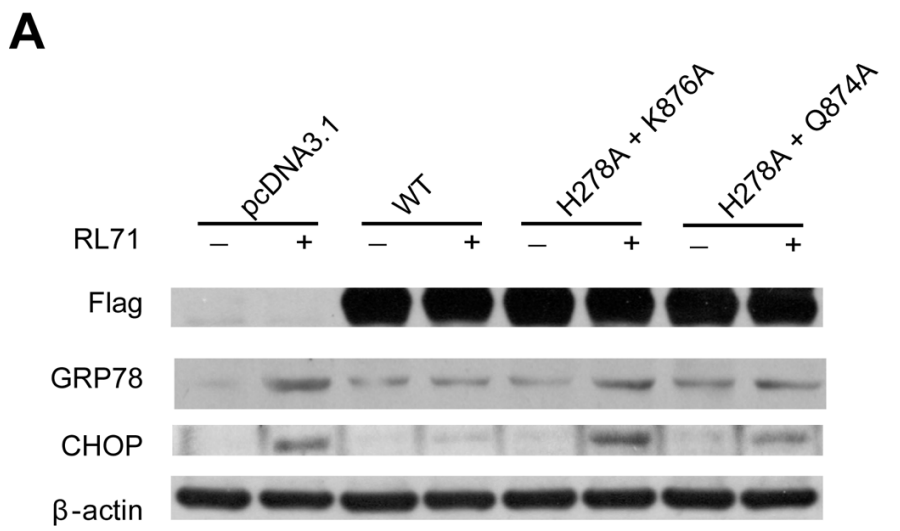

B
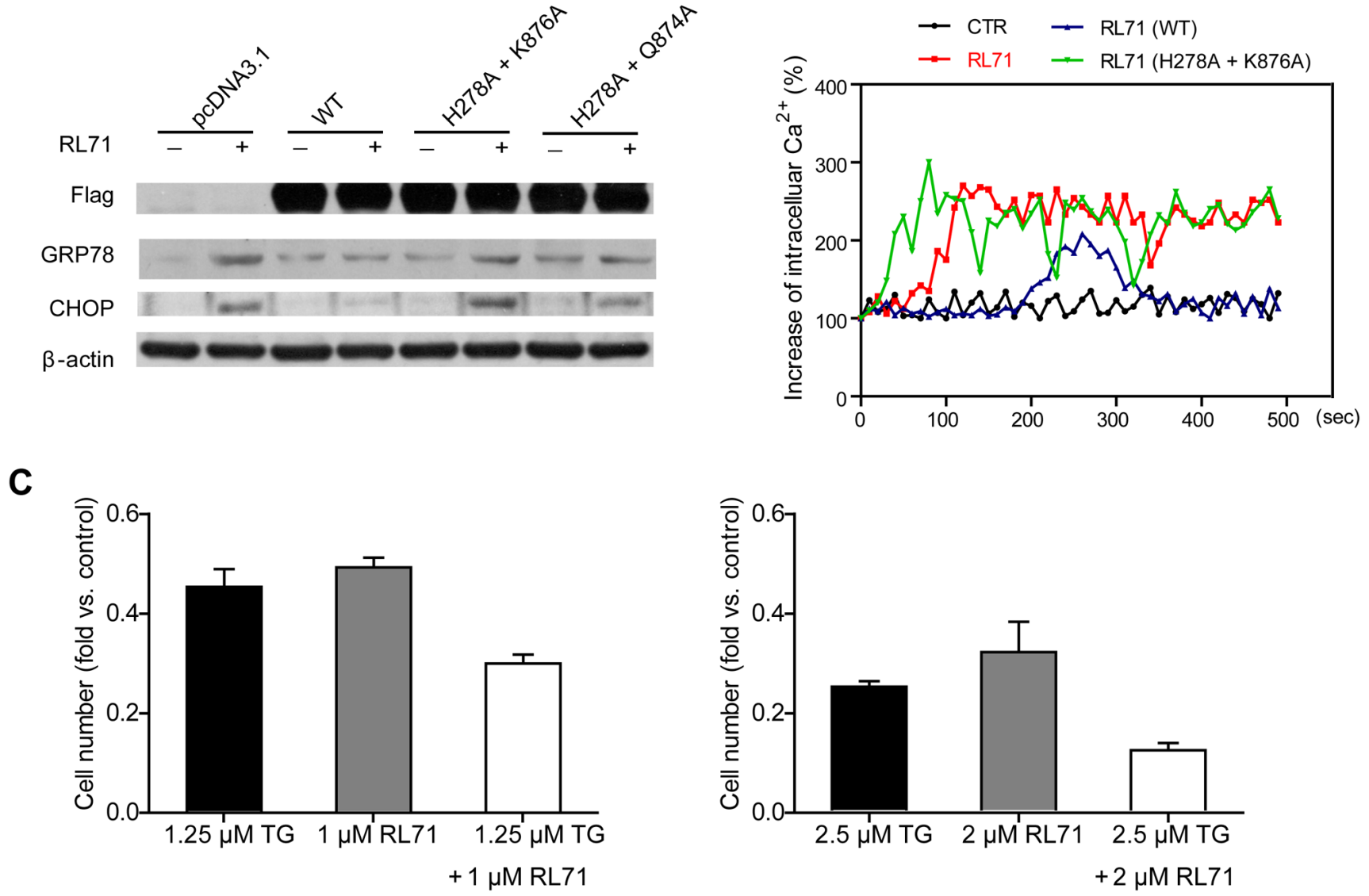

Figure 4: Binding of RL71 at a novel site contributes to ER stress-associated apoptosis. A. The effects of SERCA2 mutants within the binding site on GRP78 and CHOP expression. The HEK293 cells were transiently transfected with FLAG-tagged SERCA2b or its mutant expression plasmids. After $24 \mathrm{~h}$, the cells were incubated with $2 \mu \mathrm{M}$ of RL71 for another $24 \mathrm{~h}$. The data are representative of at least 3 experiments. B. The effects of the SERCA2 mutants on intracellular $\mathrm{Ca}^{2+}$ concentrations. Transfected HEK293 cells were loaded with Fura-2/AM and then stimulated with or without $2 \mu \mathrm{M}$ of RL71. Increasing percentages of intracellular $\mathrm{Ca}^{2+}$ concentrations were monitored. The data are representative of at least 3 experiments. C. Synergistic cytotoxicity of RL71 with thapsigargin in SW480 cells. RL71 and thapsigargin (TG) were evaluated in a cell viability assay individually and in combination at the indicated concentrations. Cell viability was determined by MTT assay after a $48 \mathrm{~h}$ treatment. The data are the mean \pm SEM of three independent experiments. 


\section{RL71 suppresses $\mathrm{SW480}$ cell growth in vivo via inhibition of SERCA2 activity}

To test RL71 activity in vivo, we subcutaneously inoculated SW480 cells into the right flank of nude mice. Two weeks later, when the tumors began to grow (approximately $50 \mathrm{~mm}^{3}$ ), the mice were randomized into 4 groups, olive oil control and RL71 (1,2 and $4 \mathrm{mg} / \mathrm{kg}$ ). As shown in Figure 6A, the administration of RL71 inhibited tumor growth compared with controls in a dose-dependent manner. When the tumors were removed on day 15 , the average weight of tumors from RL71-treated mice at the $4 \mathrm{mg} / \mathrm{kg}$ dose was 3 -fold less than the olive oil-treated

A
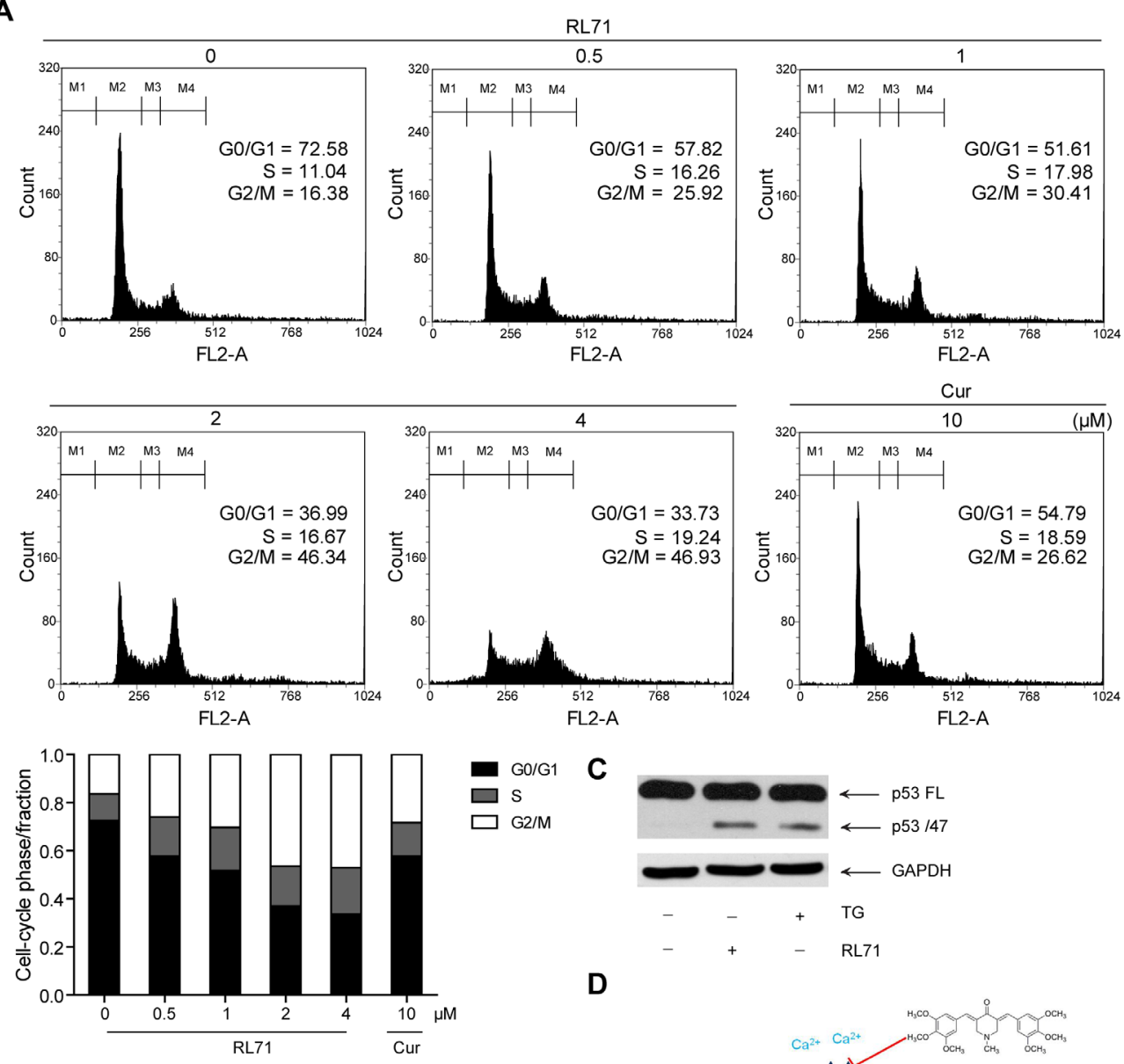

B

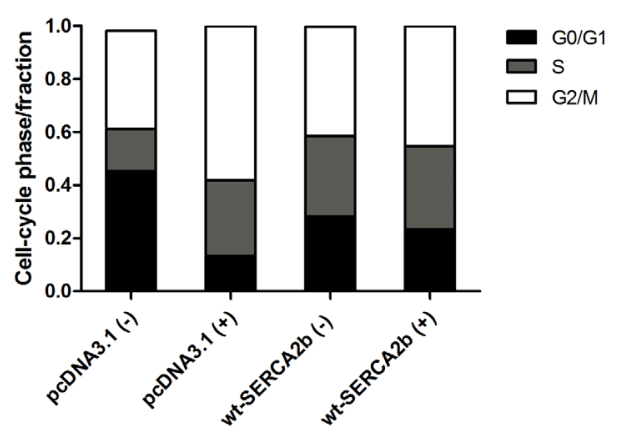

C

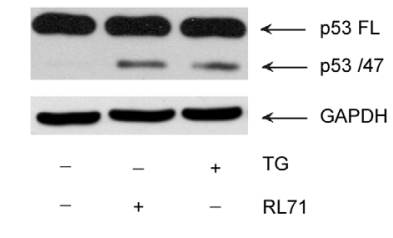

D

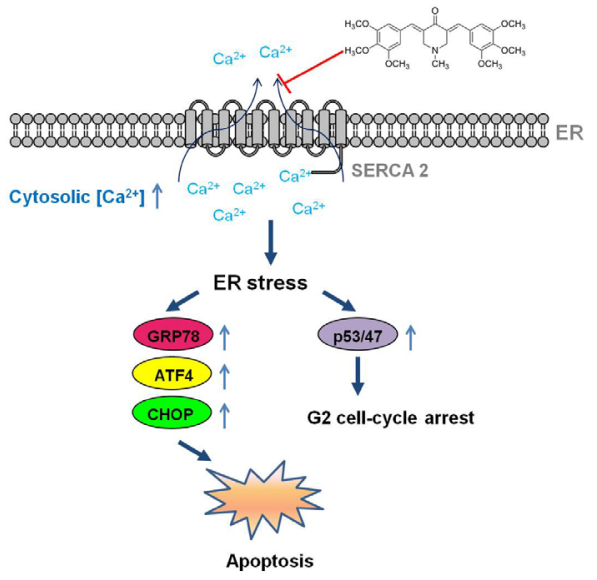

Figure 5: RL71 induces G2/M cell cycle arrest via ER stress in SW480 cells. A. G2/M cell cycle arrest in RL71-treated SW480 cells. Cells were incubated with indicated concentrations of RL71 or Cur for $24 \mathrm{~h}$. Propidium iodide staining and flow cytometry were used to determine the proportion of cells in various phases of the cell cycle. B. The effects of SERCA2 overexpression on cell cycle arrest. SW480 cells were transiently transfected with pcDNA3.1 or SERCA2b expression plasmids. After $24 \mathrm{~h}$, the cells were incubated with 2 $\mu \mathrm{M}$ of RL71 for another $24 \mathrm{~h}$. C. The protein levels of the full-length p53 (p53FL) and the p53 isoform p53/47. Cells were incubated with $2 \mu \mathrm{M}$ of RL71 or $1 \mu \mathrm{M}$ of TG for $24 \mathrm{~h}$. The data are representative of at least 3 experiments. D. Schematic representation of the mechanism by which RL71 affects ER stress-associated signaling events by targeting SERCA2. 
tumors (Figure 6B). The overall survival of the tumorbearing mice with RL71 treatment was prolonged than controls (Figure 6C). RL71 did not have significant effect on the body weight (Figure 6D), as well as the weight of the liver or spleen (Figure 6E). In addition, $\mathrm{Ca}^{2+}$-ATPase activity was inhibited by about $40 \%$ in the RL 71 -treated tumors at $2 \mathrm{mg} / \mathrm{kg}$ compared with the olive oil-treated tumors (Figure 6F), confirming SERCA2 inhibition in vivo. The cleavage of PARP and caspase 3, as well as CHOP expression in the tumors, were greatly elevated in the RL71 treatment groups (Figure 6G). Moreover, the histochemical and TUNEL staining assay showed apparent apoptotic induction in tumor tissues in the RL71-treated group at $2 \mathrm{mg} / \mathrm{kg}$ compared with the olive oil-treated group (Figure $6 \mathrm{H}$ ). Immunostaining also revealed that CD $31^{+}$-marked blood vessels in RL71-treated mice were greatly decreased compared with controls.

\section{DISCUSSION}

While targeted agents are an important part of the treatment arsenal for CRC, few small-molecule agents that target intracellular signaling pathways have been shown to improve the outcome of patients, particularly with
A

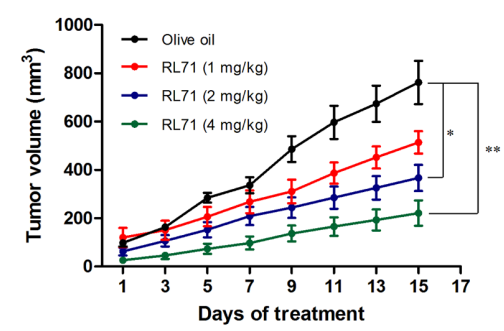

D

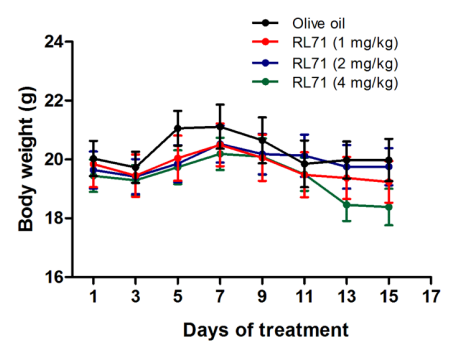

B

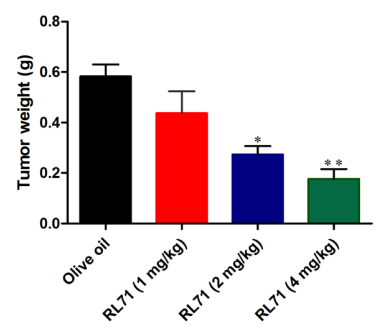

E

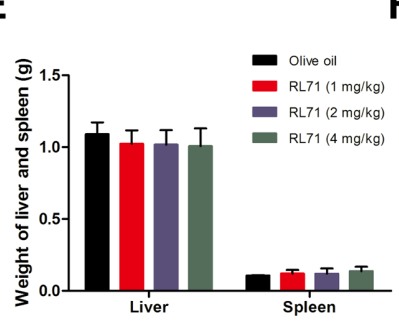

C

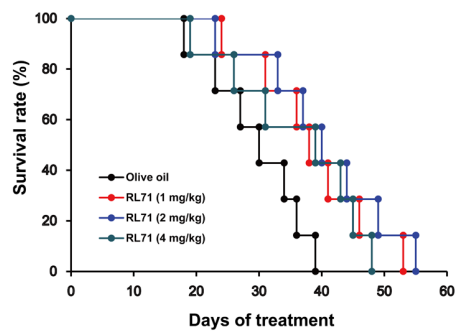

F

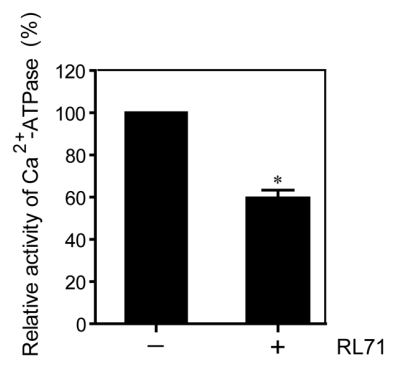

G

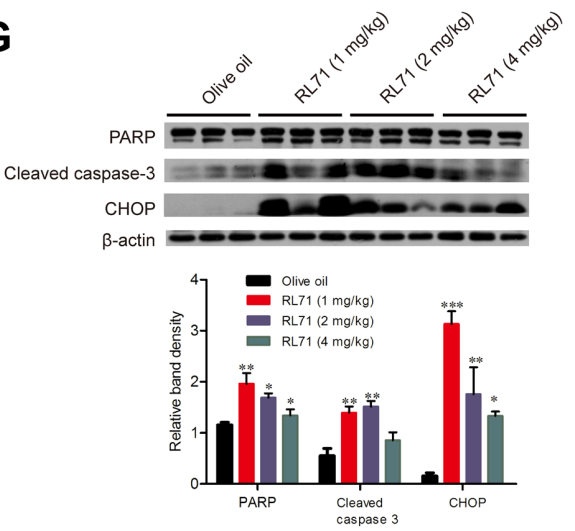

H H\&E
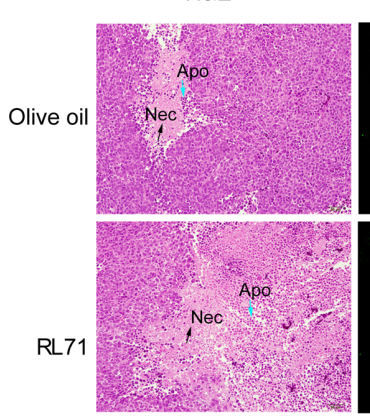

TUNEL
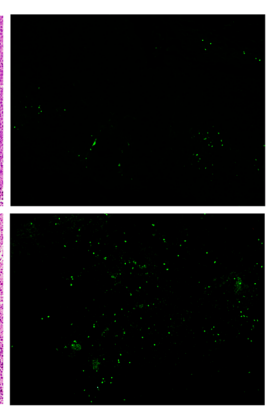

$\mathrm{IHC}$

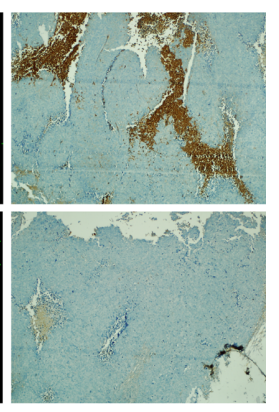

Figure 6: RL71 suppresses the growth of SW480 cells in nude mice via inhibition of SERCA2 activity. A. Tumor volumes. SW480 cells were injected subcutaneously into the right flank of nude mice. Two weeks later, the tumor-bearing mice were distributed into 4 groups and treated with various doses of RL71 or olive oil for 14 additional days. The tumor volumes were monitored and recorded every two days ( $n=8-10$ mice per group). B. Tumor weight on day 15 of treatment. C. Survival curve of mice $(n=14$ mice per group). D. Body weight. E. Weight of liver and spleen on day 15 . F. The $\mathrm{Ca}^{2+}$-ATPase activity of tumor samples from RL71-treated mice at $2 \mathrm{mg} / \mathrm{kg}$ and olive oil-treated controls. The tumor tissues were excised on day 15 and measured according to the instructions of the Ca ${ }^{2+}$-ATPase kit. G. Protein levels of PARP, cleaved caspase- 3 and CHOP in tumor samples. The tumor tissues were excised on day 15 and analyzed by western blot. H. Tumor tissues stained with H\&E (left), TUNEL reagents (middle) or an antibody specific for CD31 (right). The tumor tissues were excised on day 15. The data shown are representative of three experiments. Necrotic tumor cells (Nec) and apoptotic condensed nuclei (Apo) are indicated with arrows. Original magnification, $\times 100$. The data are the mean \pm SEM of $8-10$ mice per group. $* P<0.05$, $* * P<$ $0.01, * * * P<0.001$ versus the olive oil group. 
metastatic CRC [22]. It has been postulated that using predictive biomarkers for CRC could be indispensable for determining which patients will benefit from these target-based therapies. Our study and other recent work demonstrate that increased levels of SERCA2 expression may be a tumor marker during CRC progression [8-10]. In the present study, we report the discovery of the small molecule RL71 as a potent anti-CRC compound and identified SERCA2 as the direct target of RL71.

With a combined approach that included affinity chromatography, biochemical analysis and structural modeling, we show that RL71 binds to SERCA2 at the cleft between the loop connecting M3 and M4 and the L78 loop on the lumenal side of the ER (Figure 2). Classic panSERCA inhibitors thapsigargin and cyclopiazonic acid are both reported to bind in the transmembrane domain, and each induces unique changes to the cytoplasmic headpiece [23]. Another SERCA inhibitor, 2APB, can bind close to the cytoplasmic loop between M6 and M7 (L67) and possibly block $\mathrm{Ca}^{2+}$ from entering $\mathrm{Ca}^{2+}$-binding sites [24]. It is likely that when RL71 binds to this novel site, it acts as a 'plug,' sealing the access pathway/route by which $\mathrm{Ca}^{2+}$ can enter the ER. Mutation of the residues in the binding site revealed that the amino acid Lys876 in the L78 loop was the most critical for the specific binding of RL71 and also for the activities of RL71 acting on ER stress-related signaling and the cytosolic $\mathrm{Ca}^{2+}$ levels (Figures 2 and 4). Comparison of protein sequences of the L78 loop among the human SERCA 1-3 isoforms showed that Lys876 is only located in SERCA2 (data not shown). Because paired inhibitor studies have demonstrated that a change in SERCA conformation upon binding of a single inhibitor can favor the binding of a second inhibitor [25], a uniquely synergistic relationship was uncovered between RL71 and thapsigargin in cytotoxicity, further confirming a novel binding site for RL71. In addition, RL71 showed no inhibitory effect on the mRNA levels of SERCA3 and PMCAs that are located on the Golgi membrane and also involved in cellular $\mathrm{Ca}^{2+}$ homoeostasis (Figures S4C and S4D). Pre-inhibition of SERCA activity with TG completely abolished RL71-induced $\left[\mathrm{Ca}^{2+}\right]_{i}$ increase (Figure 3D). Taken together, these results suggest that RL71 could be a novel SERCA2-specific inhibitor.

In this study, we found that RL71 induces apoptosis and promotes G2/M cell cycle arrest in SW480 cells (Figures 3 and 5). These results could be due to the induction of ER stress by RL71 via inhibition of SERCA2. With the exception of the unfolded protein response, imbalance of $\mathrm{Ca}^{2+}$ transfer also induces ER stress [26]. SERCA inhibition causes prolonged elevation of cytosolic calcium that elicits an ER stress response typified by the accumulation of unfolded proteins, CHOP induction and caspase activation [17]. Indeed, a steady rise in cytosolic $\mathrm{Ca}^{2+}$ levels was detected in RL71-treated SW480 cells. Meanwhile, the accumulation of ubiquitinated proteins and an elevation of GRP78, ATF4 and CHOP were detected.
SERCA2 overexpression or knockdown impaired the induction of GRP78 and CHOP as well as the cleavage of PARP by RL71. It has been recently demonstrated that p53 can interact with SERCA pump at the ER, thus stimulating $\mathrm{Ca}^{2+}$ accumulation in the ER and allowing for apoptosis [27, 28]. However, RL71 inhibited SERCA2 activity and induced p53/p47 mRNA translation, suggesting that RL71 might induce p53/47-dependent G2 cell-cycle arrest via ER stress. Consistent with our results, a recent study showed that RL71 induced G2/M cell cycle arrest and apoptosis in breast cancer cells [29].

An in vivo test demonstrated that RL71 treatment dose-dependently inhibited tumor growth and reduced tumor weight in a SW480 xenograft model, but had little effect on the body weight as well as the liver or spleen weight of tumor-bearing mice (Figure 6). These results indicate that RL71 has relatively low toxicity in animals. In fact, a previous study showed that RL71 was orally available following a single oral dose of $8.5 \mathrm{mg} / \mathrm{kg}$ [29]. In line with the in vitro results, the inhibition of $\mathrm{Ca}^{2+}$ ATPase activity and the elevation of CHOP expression and apoptotic induction were detected in the RL71treated tumor tissues. Moreover, CD $31^{+}$blood vessels were greatly decreased, indicative of an anti-angiogenic microenvironment. This finding is supported by evidence that RL71 inhibits HUVEC cell migration and the ability of these cells to form tube-like networks [29]. We also found the inhibitory effect of RL71 on cell migration in SW480 cells using wound healing assay (Figure S5).

Although SERCA inhibition has been postulated to provide a potential targeting strategy for anti-cancer therapy, most small molecule SERCA inhibitors are non-selective for SERCA isoforms, which prevents their immediate clinical application. For example, TG shows toxicity in normal cells in response to SERCA inhibition [6]. Only when it was used as a prodrug by conjugation with peptides unique to prostate-specific antigen enzyme, successful targeted therapy of prostate cancer was achieved in clinical trial [3]. Curcumin is a potent SERCA2 inhibitor, but has shown limited clinical efficacy due to its low bioavailability and low stability in physiological media $[19,30,31]$. The successful synthesis of second generation heterocyclic cyclohexanone curcumin analogs affords good candidates, since they have enhanced activity and stability in biological medium compared with curcumin $[32,33]$. In this study, RL71 showed potent anti-CRC activity both in vitro and in vivo over other curcumin analogs, which is possibly related to the binding affinities for SERCA2. Furthermore, RL71 also repressed the growth of other human cancer cells (Figure S6). These results implicate its clinical therapy potential.

In summary, this study demonstrates that curcumin analog RL71 interacts with SERCA2 at a novel binding site. Thus binding might contribute to the selective potency on SERCA2 and impaired toxicity of RL71. The 
study also demonstrates the efficacy of SERCA2 as a therapeutic target for the treatment of CRC and suggests that RL71 may serve as a tool to study isoform-specific SERCA inhibition.

\section{MATERIALS AND METHODS}

\section{Reagents}

RL71, RL100 (3,5-bis(3,4,5trimethoxybenzylidene)- piperidine-4-one) , F36 (3,5-bis(3,4-dimethoxybenzylidene)- piperidine-4-one), LH60 (3, 5- di (3, 4, 5- trimethoxybenzylidene) tetrahydro2H- pyran- 4- one), LH40 (3, 4- dihydro- 4, 6- bis(3, 4, 5- trimethoxyphenyl) - $2(1 \mathrm{H})$ - pyrimidinethione) and other synthetic curcumin analogs were kindly provided by Professor Guang Liang from Wenzhou Medical College, China. These structures were confirmed by comparing MS, ${ }^{1} \mathrm{H}$ NMR and physical data with those reported in the literature $[32,34]$. The purity is higher than $97 \%$. Curcumin ( $>98 \%$ purity), 5-Diphenyl-2H-tetrazolium bromide (MTT) and thapsigargin were purchased from Sigma-Aldrich (St. Louis, MO). ER-tracker Red and Fura2/AM were purchased from Beyotime (Nanjing).

\section{Cell culture}

Human colon carcinoma cell lines SW480, SW620, HT29, HCT116 and Caco2 were purchased from the American Type Culture Collection. HEK293 cells were purchased from the Shanghai Institute of Cell Biology (Shanghai, China). The cell lines were maintained in DMEM supplemented with 10\% fetal bovine serum (FBS, Life Technologies), $100 \mathrm{U} / \mathrm{mL}$ penicillin, and $100 \mathrm{mg} /$ $\mathrm{mL}$ streptomycin and incubated at $37{ }^{\circ} \mathrm{C}$ in a humidified atmosphere containing $5 \% \mathrm{CO}_{2}$.

\section{Mice}

Eight-week-old NCR-nu / nu (nude) female mice were purchased from the Shanghai Laboratory Animal Center. Animal care was performed in compliance with the guidelines of the Ministry of Science and Technology of China (2006) and the related ethical regulations of Nanjing University. All efforts were made to minimize animal suffering and the number of animals used.

\section{Synthesis of 7}

To identify RL71-interacting proteins using affinity chromatography, RL71 conjugated with a biotin molecule was chemically synthesized. RL100 (1 mmol), biotin (1.2 mmol), TEA (1.5 mmol), EDCI (1.2 mmol), HOBt
(1.2 mmol) and DCM (20 mL) were added to an RBF. The reaction was stirred at r.t. for $16 \mathrm{~h}$. The reaction was quenched by sq. $\mathrm{NH}_{4} \mathrm{Cl}(20 \mathrm{~mL})$ and extracted with ethyl acetate $(15 \mathrm{~mL} \times 3)$. The organic phase was dried by $\mathrm{Na}_{2} \mathrm{SO}_{4}$, concentrated, then purified by flash chromatography (petroleum ether/AcOEt: $3 / 1 \mathrm{v} / \mathrm{v}$ ) to give the desired conjugate $6(72 \%)$ as a light yellow solid. ${ }^{1} \mathrm{H}$ NMR (400 MHz, $\left.\mathrm{CDCl}_{3}\right) \delta: 7.77(\mathrm{~d}, \mathrm{~J}=21.9 \mathrm{~Hz}, 2 \mathrm{H})$, $6.67(\mathrm{~d}, \mathrm{~J}=46.7 \mathrm{~Hz}, 4 \mathrm{H}), 5.63(\mathrm{~s}, 1 \mathrm{H}), 5.11(\mathrm{~s}, 1 \mathrm{H}), 4.93$ $(\mathrm{s}, 2 \mathrm{H}), 4.74(\mathrm{~s}, 2 \mathrm{H}), 4.45(\mathrm{~m}, 1 \mathrm{H}), 4.27(\mathrm{~m}, 1 \mathrm{H}), 3.91(\mathrm{~m}$, $19 \mathrm{H}), 3.05(\mathrm{~m}, 1 \mathrm{H}), 2.86(\mathrm{dd}, \mathrm{J}=12.7,4.8 \mathrm{~Hz}, 1 \mathrm{H}), 2.68$ (m, 1H), $2.22(\mathrm{t}, \mathrm{J}=7.2 \mathrm{~Hz}, 2 \mathrm{H}), 1.52(\mathrm{~m}, 4 \mathrm{H}), 1.27(\mathrm{~m}$, $3 \mathrm{H})$. ESI-MS m/z: $682[\mathrm{M}+\mathrm{H}]^{+}$.

\section{MTT assay}

Cells were incubated with various concentrations of RL71 or curcumin at a density of $2 \times 10^{4}$ cells per well in 96-well plates. In total, $20 \mu 1$ of MTT ( $4 \mathrm{mg} / \mathrm{mL}$ in PBS) was added per well $4 \mathrm{~h}$ before the end of the incubation. MTT formazan production was dissolved by DMSO replacing the medium. The optical density at $570 \mathrm{~nm}$ was measured using a FL $\times 800$ Fluorescence Microplate Reader (BioTek, Winooski, VT).

\section{Target identification of RL71 using affinity chromatography}

As described previously [35], SW480 wholecell lysates were incubated with $10 \mu \mathrm{M}$ biotin, $10 \mu \mathrm{M}$ RL71-biotin or $10 \mu \mathrm{M}$ RL71-biotin plus $200 \mu \mathrm{M}$ RL71 and $20 \mu \mathrm{l}$ streptavidin-conjugated sepharose beads (GE Healthcare) at $4{ }^{\circ} \mathrm{C}$ overnight for $12 \mathrm{~h}$. After an extensive wash with PBS, the beads were boiled in $2 \times$ loading buffer (100 mM Tris- $\mathrm{HCl}$ (pH 6.8), 4\% SDS, 1\% bromophenol blue, $20 \%$ glycerol and $2 \% \beta$-mercaptoethanol). Then, the supernatants were collected and separated with SDSPAGE prior to silver staining. The band between 95 and $130 \mathrm{kD}$ specific to RL71-biotin was excised from the gel and analyzed with LC/MS, which was performed by the Shanghai Institute of Biochemistry Proteomics Center (Shanghai).

\section{Western blot}

Western blot analysis was performed as previously described [19]. Antibodies to SERCA2 (\#9580), PARP (\#9542), cleaved caspase-3 (\#9664), DR5 (\#3696), CHOP (\#2895), p53 (\#2524), ubiquitin (\# 3933), and FLag (\# 2368) were purchased from Cell Signal Technology (Beverly, MA), and antibodies to GRP78 (sc-13968), ATF4 (sc-22800), $\beta$-actin (sc-47778) and GAPDH (sc166574) were from Santa Cruz Biotechnology (Santa Cruz, CA). Final detection was performed using the 
LumiGLO chemiluminescent substrate system (KPL, Guildford, UK).

\section{Confocal microscopy}

SW480 cells were incubated with $10 \mu \mathrm{M}$ of RL71 for $2 \mathrm{~h}$ and then fixed in 4\% paraformaldehyde ( $\mathrm{pH} 7.4$ ) for $10 \mathrm{~min}$ at $37{ }^{\circ} \mathrm{C}$. Subcelluar localization of RL71 was analyzed following the manufacturer's protocol. For analysis of the co-localization of RL71 and SERCA2, the fixed cells were stained with an anti-SERCA2 antibody and detected with a secondary antibody. The fluorescent signals were detected using a FluoViewTM FV1000 confocal microscope (Olympus Corporation, Shinjuku, Tokyo, Japan) and analyzed by the Olympus Fluview Ver1.7b viewer (Olympus Corporation, Shinjuku, Tokyo).

\section{Construction of SERCA2b and SERCA2b mutants}

The full length of human SERCA2b was subcloned into pcDNA3.1(+) as previously described in detail [19]. The amphimutation plasmids, pcDNA3.1(+)-mSERCA2b $(\mathrm{His} 278 \rightarrow$ Ala; $\quad$ Lys876 $\rightarrow$ Ala) and pcDNA3.1 $(+)$ mSERCA2b (His278 $\rightarrow$ Ala; GLN874 $\rightarrow$ Ala), were constructed by PCR-based mutagenesis using the appropriate synthetic oligonucleotides and human SERCA2b cDNA as a template. The resulting FLAGlabeled fragments were inserted into the pcDNA3.1 $(+)$ vector. All of the mutations were confirmed by sequencing.

\section{In vitro binding assay}

The HEK293 cells overexpressing FLAG-tagged SERCA2b or its mutants were lysed in protein lysis buffer (50 mM Tris-HCl, pH 7.4, $150 \mathrm{mM} \mathrm{NaCl}, 1 \%$ (v/v) Triton X-100, $5 \mathrm{mM}$ EDTA and proteinase inhibitors) and centrifuged at $16,000 \mathrm{~g}$ for $15 \mathrm{~min}$ at $4{ }^{\circ} \mathrm{C}$. The supernatant was incubated with biotin or RL71-biotin and streptavidin beads. After an extensive wash with PBS, the bound fractions were separated by SDS-PAGE and analyzed by western blotting.

\section{Intracellular $\mathrm{Ca}^{2+}$ measurement}

$\left[\mathrm{Ca}^{2+}\right]_{\mathrm{i}}$ was determined using the $\mathrm{Ca}^{2+}$-sensitive fluorescent indicator Fura-2/AM as previously described [36]. Briefly, cells were washed with HEPES-buffered medium (140 mM NaCl, $5 \mathrm{mM} \mathrm{KCl,} 1 \mathrm{mM} \mathrm{Na} \mathrm{HPO}_{4}, 1$ $\mathrm{mM} \mathrm{MgCl}{ }_{2}, 1 \mathrm{mg} / \mathrm{mL}$ glucose and $20 \mathrm{mM}$ HEPES, $\mathrm{pH}$ 7.4) and incubated with $2.5 \mu \mathrm{M}$ Fura-2/AM for $30 \mathrm{~min}$ at $37^{\circ} \mathrm{C}$. Then, the cells were washed twice and incubated with RL71 for another $15 \mathrm{~min}$. Fluorescence intensity was monitored at $510 \mathrm{~nm}$ (5 nm slit) with alternated excitation at $340 \mathrm{~nm}$ and $380 \mathrm{~nm}$ (5 $\mathrm{nm}$ slit) using a TECAN GENIOS (Model Safire; Tecan, Switzerland). [ $\left.\mathrm{Ca}^{2+}\right]$. was calculated using the formula: Intracellular free $\mathrm{Ca}^{2+}$ concentration $=\mathrm{Kd}(\mathrm{F} 0 / \mathrm{Fs})\left(\mathrm{R}-\mathrm{R}_{\min }\right) /\left(\mathrm{R}_{\max }-\mathrm{R}\right) . \mathrm{Kd}$ represents a dissociation constant with a value of $224 \mathrm{nM}$. F0 and Fs represent the fluorescence intensity measured when the $\mathrm{Ca}^{2+}$ is at zero and at the saturation point, respectively. $\mathrm{R}$ is the observed fluorescence ratio. $\mathrm{R}_{\text {max }}$ and $\mathrm{R}_{\text {min }}$ are the maximum and minimum fluorescence ratios, respectively. Maximal and minimal fluorescence values were obtained at the end of the experiment by sequential addition of $0.1 \%$ Triton X-100 and 5 mM EGTA. In some experiment, Fura-2 loaded cells were pretreated with 5 $\mu \mathrm{M}$ TG for $10 \mathrm{~min}$, followed by stimulation with RL71 in $\mathrm{Ca}^{2+}$-free medium. Changes in $\left[\mathrm{Ca}^{2+}\right]_{\mathrm{I}}$ were monitored.

\section{Lentivirus-mediated short hairpin RNA knockdown}

Lentiviral vectors HPC003cpLKD. CMV.G\&PR.U6.NC without (NC) or with a short hairpin RNA targeting SERCA2 (sh-SERCA2) were purchased from Neuronbiotech (Shang Hai). The sequence of SERCA2 shRNA is as follows: 5'-CAAAGUUCCUGCUGAUAUA-3'. SW480 cells were infected with the viral vectors and then maintained in puromycin at a concentration of $8 \mu \mathrm{g} / \mathrm{mL}$. Resistant cells were allowed to grow for 2 weeks. The cells stably expressing the shRNA were selected.

\section{Analysis of the cell cycle}

The cell cycle was analyzed by measuring propidium iodide (PI) staining using a FACSCalibur flow cytometer (Becton Dickinson, San Jose, CA). DNA contents of stained cells were analyzed with ModFit software (Becton Dickinson).

\section{Transplantation of SW480 cells into nude mice}

Cultured SW480 cells were washed with and resuspended in ice-cold PBS. Portions of the suspension (3 $\times 10^{6}$ cells in $0.1 \mathrm{~mL}$ ) were injected into the right flank of nude mice. Two weeks after the injection, the mice bearing tumors (an average size of $50 \mathrm{~mm}^{3}$ ) were distributed into 4 groups ( $n=8$-10 mice per group). RL71, dissolved in olive oil, was administered daily for 14 days by intraperitoneal injection at a dose of 1,2 or $4 \mathrm{mg} / \mathrm{kg}$. Tumor volumes were measured every 2 days and calculated using the following formula: $0.5236 \times \mathrm{L} 1 \times(\mathrm{L} 2)^{2}$, where L1 and L2 are the long and short diameters of the tumor mass, respectively. Tumor tissues, liver and spleen were excised and weighted on day 15 . In another experiment, survival tests were made ( $n=14$ mice per group) as above and 
monitored daily until all the mice died.

\section{Immunohistochemistry and TUNEL assay}

Immunostaining of CD31 was performed using a Real Envision Detection kit from the Gene Tech Company according to the manufacturer's instructions. H\&E staining in tumor tissues was performed following the manufacturer's protocol. A TUNEL assay was performed to detect apoptotic cells using the TUNEL BrightGreen Apoptosis Detection kit from Vazyme (Piscataway, NJ) according to the manufacturer's instructions.

\section{Statistical analysis}

The data are the mean \pm SEM of three independent experiments. In some experiments, statistical analyses were performed using one-way analysis of variance (ANOVA) followed by a post-hoc test. Two-way analysis of ANOVA was used in the experiments containing 2 factors. The Kaplan-Meier method was used to evaluate the survival rate. $P<0.05$ was considered significant.

\section{ACKNOWLEDGMENTS}

This study was supported by the National Natural Science Foundation of China (Nos. 90913023, 81573446, $31370900,81273569)$, the Natural Science Foundation of Jiangsu Province (No. BK20131282) and the Jiangsu Province Clinical Science and Technology Project (Clinical Research Center, BL2012008).

\section{CONFLICTS OF INTERESTS}

The authors have no financial conflicts of interest.

\section{REFERENCES}

1. Siegel R, Naishadham D and Jemal A. Cancer statistics, 2013. CA: a cancer journal for clinicians. 2013; 63:11-30.

2. Monteith GR, McAndrew D, Faddy HM and RobertsThomson SJ. Calcium and cancer: targeting Ca2+ transport. Nature reviews Cancer. 2007; 7:519-530.

3. Christensen SB, Skytte DM, Denmeade SR, Dionne C, Moller JV, Nissen P and Isaacs JT. A Trojan horse in drug development: targeting of thapsigargins towards prostate cancer cells. Anti-cancer agents in medicinal chemistry. 2009; 9:276-294.

4. Roti G, Carlton A, Ross KN, Markstein M, Pajcini K, Su AH, Perrimon N, Pear WS, Kung AL, Blacklow SC, Aster JC and Stegmaier K. Complementary genomic screens identify SERCA as a therapeutic target in NOTCH1 mutated cancer. Cancer cell. 2013; 23:390-405.

5. Arbabian A, Brouland JP, Gelebart P, Kovacs T, Bobe R,
Enouf J and Papp B. Endoplasmic reticulum calcium pumps and cancer. BioFactors. 2011; 37:139-149.

6. Denmeade SR and Isaacs JT. The SERCA pump as a therapeutic target: making a "smart bomb" for prostate cancer. Cancer biology \& therapy. 2005; 4:14-22.

7. Korosec B, Glavac D, Rott $\mathrm{T}$ and Ravnik-Glavac M. Alterations in the ATP2A2 gene in correlation with colon and lung cancer. Cancer genetics and cytogenetics. 2006; 171:105-111.

8. Chung FY, Lin SR, Lu CY, Yeh CS, Chen FM, Hsieh JS, Huang TJ and Wang JY. Sarco/endoplasmic reticulum calcium-ATPase 2 expression as a tumor marker in colorectal cancer. The American journal of surgical pathology. 2006; 30:969-974.

9. Huang MY, Wang HM, Tok TS, Chang HJ, Chang MS, Cheng TL, Wang JY and Lin SR. EVI2B, ATP2A2, S100B, TM4SF3, and OLFM4 as potential prognostic markers for postoperative Taiwanese colorectal cancer patients. DNA and cell biology. 2012; 31:625-635.

10. Fan L, Li A, Li W, Cai P, Yang B, Zhang M, Gu Y, Shu Y, Sun Y, Shen Y, Wu X, Hu G, Wu X and Xu Q. Novel role of Sarco/endoplasmic reticulum calcium ATPase 2 in development of colorectal cancer and its regulation by F36, a curcumin analog. Biomedicine \& pharmacotherapy $=$ Biomedecine \& pharmacotherapie. 2014; 68:1141-1148.

11. Brouland JP, Gelebart P, Kovacs T, Enouf J, Grossmann $\mathrm{J}$ and Papp B. The loss of sarco/endoplasmic reticulum calcium transport ATPase 3 expression is an early event during the multistep process of colon carcinogenesis. The American journal of pathology. 2005; 167:233-242.

12. Gou WF, Niu ZF, Zhao S, Takano Y and Zheng HC. Aberrant SERCA3 expression during the colorectal adenoma-adenocarcinoma sequence. Oncology reports. 2014; 31:232-240.

13. Michelangeli F and East JM. A diversity of SERCA Ca2+ pump inhibitors. Biochemical Society transactions. 2011; 39:789-797.

14. Ghantous A, Gali-Muhtasib H, Vuorela H, Saliba NA and Darwiche N. What made sesquiterpene lactones reach cancer clinical trials? Drug discovery today. 2010; 15:668678.

15. Wootton LL and Michelangeli F. The effects of the phenylalanine 256 to valine mutation on the sensitivity of sarcoplasmic/endoplasmic reticulum $\mathrm{Ca} 2+$ ATPase (SERCA) $\mathrm{Ca} 2+$ pump isoforms 1,2 , and 3 to thapsigargin and other inhibitors. The Journal of biological chemistry. 2006; 281:6970-6976.

16. Toyoshima C, Nakasako $M$, Nomura $H$ and Ogawa $H$. Crystal structure of the calcium pump of sarcoplasmic reticulum at 2.6 A resolution. Nature. 2000; 405:647-655.

17. Orrenius S, Zhivotovsky B and Nicotera P. Regulation of cell death: the calcium-apoptosis link. Nature reviews Molecular cell biology. 2003; 4:552-565.

18. Ozcan U, Yilmaz E, Ozcan L, Furuhashi M, Vaillancourt 
E, Smith RO, Gorgun CZ and Hotamisligil GS. Chemical chaperones reduce ER stress and restore glucose homeostasis in a mouse model of type 2 diabetes. Science. 2006; 313:1137-1140.

19. Wang L, Wang L, Song R, Shen Y, Sun Y, Gu Y, Shu Y and $\mathrm{Xu} \mathrm{Q}$. Targeting sarcoplasmic/endoplasmic reticulum $\mathrm{Ca}(2)+$-ATPase 2 by curcumin induces ER stress-associated apoptosis for treating human liposarcoma. Molecular cancer therapeutics. 2011; 10:461-471.

20. Winther AM, Liu H, Sonntag Y, Olesen C, le Maire M, Soehoel H, Olsen CE, Christensen SB, Nissen P and Moller JV. Critical roles of hydrophobicity and orientation of side chains for inactivation of sarcoplasmic reticulum $\mathrm{Ca} 2+$ ATPase with thapsigargin and thapsigargin analogs. The Journal of biological chemistry. 2010; 285:28883-28892.

21. Bourougaa K, Naski N, Boularan C, Mlynarczyk C, Candeias MM, Marullo S and Fahraeus R. Endoplasmic reticulum stress induces $\mathrm{G} 2$ cell-cycle arrest via mRNA translation of the p53 isoform p53/47. Molecular cell. 2010; 38:78-88.

22. Burotto M, Hartley ML, Marshall JL and Pishvaian MJ. Future of targeted agents in metastatic colorectal cancer. Colorectal cancer. 2012; 1:16.

23. Takahashi M, Kondou $\mathrm{Y}$ and Toyoshima C. Interdomain communication in calcium pump as revealed in the crystal structures with transmembrane inhibitors. Proceedings of the National Academy of Sciences of the United States of America. 2007; 104:5800-5805.

24. Bilmen JG, Wootton LL, Godfrey RE, Smart OS and Michelangeli F. Inhibition of SERCA Ca2+ pumps by 2-aminoethoxydiphenyl borate (2-APB). 2-APB reduces both $\mathrm{Ca} 2+$ binding and phosphoryl transfer from ATP, by interfering with the pathway leading to the Ca2+-binding sites. European journal of biochemistry / FEBS. 2002; 269:3678-3687.

25. Logan-Smith MJ, East JM and Lee AG. Evidence for a global inhibitor-induced conformation change on the $\mathrm{Ca}(2+)$-ATPase of sarcoplasmic reticulum from paired inhibitor studies. Biochemistry. 2002; 41:2869-2875.

26. Ferri KF and Kroemer G. Organelle-specific initiation of cell death pathways. Nature cell biology. 2001; 3:E255-263.

27. Haupt S, Raghu D and Haupt Y. p53 Calls upon CIA (Calcium Induced Apoptosis) to Counter Stress. Frontiers in oncology. 2015; 5:57.

28. Giorgi C, Bonora M, Sorrentino G, Missiroli S, Poletti F, Suski JM, Galindo Ramirez F, Rizzuto R, Di Virgilio F, Zito E, Pandolfi PP, Wieckowski MR, Mammano F, Del Sal $\mathrm{G}$ and Pinton P. p53 at the endoplasmic reticulum regulates apoptosis in a $\mathrm{Ca} 2+$-dependent manner. Proceedings of the National Academy of Sciences of the United States of America. 2015; 112:1779-1784.

29. Yadav B, Taurin S, Larsen L and Rosengren RJ. RL71, a second-generation curcumin analog, induces apoptosis and downregulates Akt in ER-negative breast cancer cells.
International journal of oncology. 2012; 41:1119-1127.

30. Carroll RE, Benya RV, Turgeon DK, Vareed S, Neuman M, Rodriguez L, Kakarala M, Carpenter PM, McLaren C, Meyskens FL, Jr. and Brenner DE. Phase IIa clinical trial of curcumin for the prevention of colorectal neoplasia. Cancer prevention research. 2011; 4:354-364.

31. Bilmen JG, Khan SZ, Javed $\mathrm{MH}$ and Michelangeli $\mathrm{F}$. Inhibition of the SERCA $\mathrm{Ca} 2+$ pumps by curcumin. Curcumin putatively stabilizes the interaction between the nucleotide-binding and phosphorylation domains in the absence of ATP. European journal of biochemistry / FEBS. 2001; 268:6318-6327.

32. Yadav B, Taurin S, Rosengren RJ, Schumacher M, Diederich M, Somers-Edgar TJ and Larsen L. Synthesis and cytotoxic potential of heterocyclic cyclohexanone analogues of curcumin. Bioorganic \& medicinal chemistry. 2010; 18:6701-6707.

33. Liang G, Shao L, Wang Y, Zhao C, Chu Y, Xiao J, Zhao $\mathrm{Y}, \mathrm{Li} \mathrm{X}$ and Yang S. Exploration and synthesis of curcumin analogues with improved structural stability both in vitro and in vivo as cytotoxic agents. Bioorganic \& medicinal chemistry. 2009; 17:2623-2631.

34. Wu J, Zhang Y, Cai Y, Wang J, Weng B, Tang Q, Chen $X$, Pan Z, Liang G and Yang S. Discovery and evaluation of piperid-4-one-containing mono-carbonyl analogs of curcumin as anti-inflammatory agents. Bioorganic \& medicinal chemistry. 2013; 21:3058-3065.

35. Li W, Ouyang Z, Zhang Q, Wang L, Shen Y, Wu X, Gu Y, Shu Y, Yu B, Wu X, Sun Y and Xu Q. SBF-1 exerts strong anticervical cancer effect through inducing endoplasmic reticulum stress-associated cell death via targeting sarco/ endoplasmic reticulum $\mathrm{Ca}(2+)$-ATPase 2 . Cell death \& disease. 2014; 5:e1581.

36. $\mathrm{Li} \mathrm{XH}$ and $\mathrm{Wu}$ YJ. Characteristics of lysophosphatidylcholine-induced $\mathrm{Ca} 2+$ response in human neuroblastoma SH-SY5Y cells. Life sciences. 2007; 80:886-892. 